\title{
Editorial 21/4
}

\author{
Hubert Österle • Karen Heyden
}

Published online: 25 November 2011

(C) Institute of Information Management, University of St. Gallen 2011

Dear Readers of Electronic Markets, Welcome to the fourth issue of Electronic Markets' twentyfirst volume. You might recall that our last issue was dedicated to the area of social media. Following this trend, we have also decided to use this innovative form of interaction for Electronic Markets and would like to invite you to visit EM on Facebook (facebook.com/ElectronicMarkets) as well as on Twitter (twitter.com/journal_EM). We are excited about these new possibilities and hope that many of you will join us in this effort.

Among others, the social media postings also comprise the announcements of our latest issues and the dedicated special theme. The present issue differs in this regard as it presents a collection of four general research articles on customer-related topics.

The first is titled "Service Integrators in Business Networks - The importance of Relationship Values" and is authored by Bernd Heinrich, Gregor Zellner and Susanne J. Leist. They provide a novel approach to systematically designing relationships within business networks. The main idea is that transaction-orientation needs to be replaced by a focus on longer-term relationships and that service integrators are an essential element in this transformation process. Using the example of a financial service network the paper provides an impression of how relationship-orientation may be designed and applied in practice.

The second contribution takes a closer look at customer relationships by adapting a concept from psychology. Jamie

\footnotetext{
H. Österle $(\bowtie)$

Institute of Information Management, University of St. Gallen, Müller-Friedberg-Strasse 8,

CH-9000 St. Gallen, Switzerland

e-mail: hubert.oesterle@unisg.ch

\section{K. Heyden}

Information Systems Institute, University of Leipzig,

Grimmaische Str. 12,

04109 Leipzig, Germany

e-mail: heyden@wifa.uni-leipzig.de
}

Carlson and Aron O'Cass present the results of their research on "Creating Commercially Compelling Website-Service Encounters" which aims to analyze the services offered by websites using an interdisciplinary perspective. The authors present a survey of customers from the professional sporting and e-retailing sector which yields insights into factors which generate the sensation of flow.

Another paper from the customer domain is written by Soonyong Bae and Taesik Lee. Their article on "Product Type and Consumers' Perception of Online Consumer Reviews" argues that while the Internet has the potential to reduce search costs for online consumers, it is difficult to obtain comprehensive information about so-called experience products. Online consumer reviews are presented as a helpful source of product information before purchasing. In particular, the origin of the reviews and the types of products are identified as relevant for the consumers' perception of a review. They suggest distinguishing between marketerdeveloped and consumer-developed internet sites.

The fourth paper reports on "Online buying perceptions in Spain" and analyzes whether gender makes a difference in the context of online buying. The authors Sonia San Martín and Nadia Jiménez identified the behavior of male and female online consumers based on four specific signals which represent website characteristics. Among the results from their survey of 533 Spanish online shoppers are gender specifics regarding satisfaction and trust. In their conclusions, the authors develop several recommendations for e-vendors. .

As usual, we would like to thank all authors, reviewers and editors for their effort involved in this issue. We hope you enjoy reading this issue of Electronic Markets. Of course, any feedback on the journal or single contributions is greatly appreciated.

Best regards,

Your Electronic Markets editorial team

Hubert Österle

Karen Heyden 